Jurnal IImiah AL-Jauhari (JIAJ)

Volume 2 No 2, Desember 2017

ISSN: $2541-3430$

E-ISSN: 2541-3449

Halaman 131-143

\title{
Norma dan Aktualisasi Peace Education dalam Dakwah Nabi Muhammad SAW Periode Mekkah dan Madinah: Studi Komparasi antara Materi MA dan SMA
}

\author{
Chaterina Puteri Doni \\ Universitas Muhammadiyah Gorontalo \\ Email: Chaterina14101988@,gmail.com
}

\begin{abstract}
Abstrak
Secara faktual, moralitas dan karakter bangsa, khususnya di kalangan pelajar tingkat SLTA saat ini telah mulai runtuh. Hal ini terbukti dengan tingginya tingkat kekerasan seperti tawuran, pelecehan seksual dan perkelahian di dunia pendidikan. Isu-isu utama tersebut bukanlah sesuatu yang bisa dianggap sepele. Kasus-kasus yang terjadi di kalangan pelajar saat ini telah masuk dalam kategori sangat memprihatinkan bahkan tidak sedikit yang berurusan dengan aparat hukum. Dalam kondisi seperti ini, yang dibutuhkan adalah melalui pendidikan yang berbasis perdamaian atau pendidikan perdamaian. Dalam hal ini pendidikan perdamaian dianggap sebagai salah satu solusi alternatif dari masalah yang terjadi saat ini.

interpretasi nilai peace education dalam dakwah Nabi Muhammad saw periode Mekkah adalah tanggung jawab, persamaan derajat, keadilan, kash sayang dan toleransi. Sedangkan nilai peace education periode Madinah adalah; Hak asasi manusia, persamaan, keadilan, demokrasi, toleransi, empati. Ketiga, dalam aktualisasi nilai pendidikan perdamaian dalam dakwah Nabi Muhammad saw periode Mekkah dan Madinah ditemukan terdapat adanya perbedaan mendasar dalam materi dakwah Nabi Muhammad saw, periode Madinah materi MA lebih komprehensif dan detail sedangkan tingkat SMA lebih bersifat umum dan tidak detail, sehingga beberapa nilai pendidikan perdamaian tidak terangkum di dalamnya. Sehingganya dalam penelitian ini dapat memberikan sumbangsi dalam hal perbaikan kurikulum ataupun materi pelajaran kedepan.
\end{abstract}

Kata kunci: Aktualisasi, Nilai, Peace Education

\section{Pendahuluan}

Secara faktual, moralitas maupun karakter bangsa khususnya pelajar saat ini telah mulai runtuh. Runtuhnya moralitas dan karakter bangsa tersebut telah mengundang berbagai musibah dan bencana di negeri ini. Musibah dan bencana 
tersebut telah meluas bukan hanya pada ranah sosial dan potik namun telah merambat ke dunia pendidikan. Kekerasan dalam dunia pendidikan saat ini telah menjadi isu utama yang tidak bisa disepelekan. Kasus-kasus yang terjadi di kalangan pelajar saat ini telah masuk dalam kategori sangat memprihatinkan.

Fenomena di atas telah menjadi salah satu tolak ukur bahwa tindak kekerasan yang terjadi saat ini bukanlah sebuah hal yang baru, namun telah ada dan terjadi disekitar kita serta yang menjadi korban adalah peserta didik yang terdapat di lingkungan tempat tinggal maupun lingkungan kerja. Atas dasar itu untuk mengantisipasi berulangnya kasus tindak kekerasan dikalangan pelajar atau dunia pendidikan dalam skala yang lebih besar, bahkan bisa terajdi berlarut-larut, diperlukan upaya pencegahan melalui studi pendidikan. Atas dasar inilah sehingga studi perdamaian sangat memiliki peranan yang penting dalam membentuk perilaku melalui jalur pendidikan

\section{Peace Education}

Peace Education memiliki dua pecahan kata yaitu peace dan education yang keduanya memiliki makna yang berbeda. Peace berarti freedom from war or violence; a peace formula plan/movement treaty (Hornby, 1995: 852) (kebebasan dari perang atau kekerasan; rencana rumusan perdamaian/gerakan perjanjian). Sedangkan Education berarti a process of training and instruction (proses pelatihan dan instruksi). Jadi dapat disimpulkan peace education adalah pendidikan perdamaian. Maksudnya, pendidikan akan diarahkan kepada pengembangan pribadi manusia untuk lebih menghormati dan mencintai sebuah perdamaian.

Definisi di atas menunjukkan akan pentingnya pendidikan pada konteks heterogenitas manusia dengan dasar hak asasi setiap orang untuk diakui dan dihormati, kemudian perlunya saling memahami, toleransi, dan berhubungan walaupun berbeda bangsa, ras, ataupun agama, tetapi tetap dalam lingkaran yang sama yaitu perdamaian.

Disebabkan perdamaian dianggap penting, maka UNESCO (United Nations of Education, Scietific, and Cultural Organization) pada tahun 1974 mengambil langkah untuk mengembangkan melalui jalur pendidikan agar menjadi pendekatan yang utuh. Pernyataan itu berbunyi, "UNESCO recommendation concerning education for international, understanding, cooperation, and peace and education relating to human right and fundamental freedoms"(rekomendasi mengenai pendidikan bagi internasional, pemahaman, kerjasama, dan perdamaian pendidikan yang berkaitan dengan hak asasi manusia dan kebebasan fundamental). Wujud dari pernyataan UNESCO tersebut berlanjut dalam bentuk konstitusi yang berisi perintah untuk membangun budaya perdamaian dalam setiap pemikiran orang yang hidup di dunia (in the minds of men). Di sini juga disebutkan tentang budaya perdamaian (culture of peace) menurut UNESCO tahun 1992, yaitu value, attitude, behavior and ways of life based on non violence and respect for fundamental right and freedoms, on understanding, tolerance and solidaryty, on the sharing, and free flow of information, and the full participation and empowerment of women (UNESCO, 2001: 17), (budaya perdamaian merupakan bagian dari nilai, sikap, perilaku, dan cara hidup yang didasarkan pada 
penolakan kekerasan dan hormat terhadap hak asasi manusia serta kebebasan, pemahaman, toleransi, dan solidaritas, saling berbagi, dan bebas memperoleh informasi dan penuh partisipasi serta kesempatan bagi wanita).

Peace education telah dikembangkan sebagai tujuan utama yang harus dicapai. Hal ini berarti pendidikan diarahkan untuk pengembangan kepribadian manusia dan memperkuat rasa hormat kepada hak asasi serta kebebasan mendasar, tujuannya untuk saling memahami, toleransi, dan persahabatan antar semua bangsa, ras, atau kelompok agama dan memperkuat aktivitas untuk memelihara perdamaian.

Kesimpulannya, bahwa peace education adalah pendidikan yang diarahkan kepada pengembangan kepribadian manusia, menghormati hak asasi manusia, adanya kebebasan yang mendasar, saling pengertian, toleransi dan menjalin persahabatan dengan semua bangsa, ras, dan antar kelompok yang mengarah pada perdamaian. Dengan melalui proses pendidikanlah perdamaian bisa dibangun dengan kukuh di atas landasan penghargaan atas perbedaan-perbedaan yang ada.

Jika merujuk pada uraian pendidikan tersebut, maka tindakan kekerasan yang dilakukan oleh manusia merupakan tindakan yang keji dan merugikan diri sendiri maupun orang lain. Dengan ungkapan lain, kekerasan adalah wujud dari kehampaan akan eksistensi sebagai manusia yang bertanggung jawab. Kesadaran inilah yang perlu ditanamkan melalui pendidikan. Pendidikan tidak hanya berperan sebagai arena transfer ilmu pengetahuan, tetapi juga sebagai wahana untuk menumbuhkan kesadaran jati diri dan peran manusia yang harus diemban. Berdasarkan hal inilah, usaha untuk mewujudkan perdamaian tidak hanya untuk mengurangi tindak kekerasan, tetapi juga adanya ikhtiar untuk mewujudkan rasa tentram, harmonis, dan damai dalam realitas kehidupan sosial.

Dalam dakwah Nabi Muhammad SAW Pendidikan Islam pada Masa Nabi Muhammad SAW terbagi dua periode, yaitu Makkah dan Madinah, intisari pendidikan Islam pada periode itu disandarkan pada Al-Quran dan Sunnah Rasul adalah Guru, pelopor pendidikan Islam. Dari sana titik awal perkembangan pendidikan Islam dimulai.

Undang-undang No. 20 tahun 2003 tentang Sistem Pendidikan Nasional, menyatakan bahwa pendidikan nasional berfungsi mengembangkan kemampuan dan membentuk watak serta peradaban bangsa yag bermartabat dalam rangka mencerdaskan kehidupan bangsa, bertujuan untuk berkembangnya potensi peserta didik agar menjadi manusia yang beriman dan bertakwa kepada Tuhan Yang Maha Esa, berkahlak mulia, sehat, berilmu, cakap, kreatif, mandiri, dan menjadi warga negara yang demokratis serta bertanggung jawab. Untuk mencapai tujuan tersebut, salah satu bidang studi yag harus dipelajari oleh peserta didik di madrasah adalah Pendidikan agama Islam, yang dimaksudkan untuk membentuk peserta didik menjadi manusia yang beriman dan bertakwa serta berakhlak mulia. Pendidikan Agama Islam di Madrasah Aliyah terdiri atas empat mata pelajaran, yaitu: Al-Quran-Hadis, Akidah-Akhlak, Fikih dan Sejarah Kebudayaan Islam. Masing-masing mata pelajaran tersebut pada dasarnya saling terkait, isi mengisi dan melengkapi. Al-Quran-Hadis merupakan sumber utama ajaran Islam, dalam arti ia merupakan sumber akidah-akhlak, syari ah/fikih (ibadah, muamalah) atau keimanan merupakan akar atau pokok agama. Syaria ah/fikih (ibadah, muamalah) 
dan akhlak bertitik tolak dari akidah, yakni sebagai manifestasi dan konsekuensi dari akidah (keimanan dan keyakinan hidup). Syariah/fikih merupakan sistem norma (aturan) yang mengatur hubungan manusia dengan Allah, sesama manusia dan dengan makhluk lainnya. Akhlak merupakan aspek sikap hidup atau kepribadian hidup manusia, dalam arti bagaimana sistem norma yang mengatur hubungan manusia dengan Allah (ibadah dalam arti khas) dan hubungan manusia dengan manusia dan lainnya (muamalah) itu menjadi sikap hidup dan kepribadian hidup manusia dalam menjalankan sistem kehidupannya (politik, ekonomi, sosial, pendidikan, kekeluargaan, kebudayaan/seni, iptek, olahraga/kesehatan) yang dilandasi oleh akidah yang kokoh. Searah kebudayaan Islam merupakan perkembangan perjalanan hidup manusia muslim dari masa ke masa dalam usaha bersyariah (beribadah dan bermuamalah) dan berakhlak serta dalam mengembangkan sistem kehidupannya yang dilandasi oleh akidah.

Pendidikan Agama Islam (PAI) di Madrasah Aliyah yang terdiri atas empat mata pelajaran tersebut memiliki karakteristik sendiri-sendiri. Al-QuranHadis, menekankan pada kemampuan baca tulis yang baik dan benar, memahami makna secara tekstual dan konteksrtual, serta mengamalkan kandungannya dalam kehidupan sehari-hari. Aspek kaidah menekankan pada kemampuan memahami dan mempertahankan keyakinan/keimanan yang benar serta menghayati dan mengamalkan nilai-nilai al-asma' al-husna. Aspek akhlak menekankan pada pembiasaan untuk melaksanakan akhlak terpuji dan menjauhi akhlak tercela dalam kehidupan sehari-hari. Aspek sejarah Kebudayaan Islam menekankan pada kemampuan mengambil ibrah dari peristiwa-peristiwa bersejarah (Islam), meneladani tokoh-tokoh berprestasi dan mengaitkannya dengan fenomena sosial, budaya, politik, ekonomi, iptek, dan seni dan lain-lain untuk mengembangkan Kebudayaan dan peradaban Islam.

Sejarah Kebudayaan Islam di Madrasah Aliyah merupakan salah satu mata pelajaran yang menelaah tentang asal-usul, perkembangan, peranan kebudayaan/perdaban Islam di masa lampau, mulai dari dakwah Nabi Muhammad SAW pada periode Makkah dan periode Madinah, kepemimpinan umat setelah Rasulullah SAW wafat, sampai perkembangan Islam periode klasik (zaman keemasan) pada tahun $650 \mathrm{M}-1250 \mathrm{M}$, abad pertengahan/zaman kemunduran (1250M-1800M), dan masa modern/zaman kebangkitan (1800-sekarang), serta perkembangan Islam di Indonesia dan di Dunia. Secara substansial mata pelajaran Sejarah Kebudayaan Islam memiliki kontribusi dalam memberikan motivasi kepada peserta didik untuk mengenal, memahami, menghayati Sejarah Kebudayaan Islam, yang mengandung nilai-nilai kearifan yang dapat digunakan untuk melatih kecerdasan, membentuk sikap, watak, dan kepribadian peserta didik.

Mata pelajaran Sejarah Kebudayaan Islam di Madrasah Aliyah bertujuan agar peserta didik memiliki kemampuan-kemampuan sebagai berikut:

a. Membangun kesadaran peserta didik tentang pentingnya mempelajari landasan agama, nilai-nilai dan norma-norma Islam yang telah dibangun oleh Rasulullah SAW dalam rangka mengembangkan kebudayaan dan perdaban Islam. 
b. Membangun kesadaran peserta didik tentang pentingnya waktu dan tempat yang merupakan sebuah proses dari masa lalu, masa kini, dan masa depan

c. Melatih daya kritis peserta didik untuk mamahami fakta sejarah secara benar dengan didasarkan pada pendekatan ilmiah.

d. Menumbuhkan apresiasi dan penghargaan peserta didik terhadap peninggalan sejarah Islam sebagai bukti peradaban umat Islam di masa lampau.

e. Mengembangkan kemampuan peserta didik dalam mengambil ibrah dari peristiwa-peristiwa bersejarah (Islam), meneladani tokoh-tokoh berprestasi, dan mengaitkannya dengan fenomena sosial, budaya politik, ekonomi, iptek dan seni dan lain-lain untuk mengemangkan Kebudayaan dan peradaban Islam.

Materi mengenai kehidupan Nabi Muhammad SAW, adalah materi yang menyangkut dengan sejarah kehidupan nabi, yang termasuk dalam kajian sejarah kebudayaan Islam, sejarah kehidupan nabi yang dimaksudkan dalam penelitian ini adalah materi mengenai Dakwah Nabi Muhammad SAW periode Mekkah dan Madinah.

1. Analisis nilai peace education dalam materi dakwah Nabi Muhammad saw periode Mekkah dan Madinah tingkat MA dan SMA

Berdasarkan analisis peneliti mengenai nilai pendidikan perdamaian yang terdapat dalam materi Dakwah Nabi Muhammad saw periode Mekkah dan Madinah tingkat MA dan SMA, beberapa nilai pendidikan perdamaian yang peneliti dapatkan yaitu:

a. Nilai peace education dalam materi dakwah Nabi Muhammad saw periode Mekkah dan Madinah tingkat MA

Materi dakwah Nabi Muhammad saw periode Mekkah dan Madinah tingkat MA berdasarkan hasil analisis menyangkut materi-materi yang memiliki nilai dari pendidikan perdamaian adalah sebagai berikut:

\begin{tabular}{|c|c|}
\hline \multicolumn{2}{|r|}{ Nilai pendidikan perdamaian } \\
\hline & Tingkat MA \\
\hline $\begin{array}{l}\text { 1. Aspek Kognitif } \\
\text { a. Persatuan dan } \\
\text { Persamaan }\end{array}$ & $\begin{array}{l}\text { Dalam Nilai Dan Aktualisasi Dari Pendidikan } \\
\text { Perdamaian: } \\
\text { “.....Rasulullah saw Telah Menciptakan Suatu } \\
\text { Persaudaraan Baru Yaitu Persaudaraan Berdasarkan } \\
\text { Agama Yang Menggantikan Persaudaraan Yang } \\
\text { Berdasarkan Darah” (Periode Madinah) } \\
\text { “...Rasulullah Tidak Membedakan Kasta Atau } \\
\text { Derajat Dari Seseorang, Nabi Menyeratakan Semua } \\
\text { Kedudukan Umat Dimata Hukum Maupun Agama” } \\
\text { (Periode Mekkah) }\end{array}$ \\
\hline $\begin{array}{l}\text { 2. Aspek } \\
\text { Psikomotorik } \\
\text { a. Kasih Sayang } \\
\end{array}$ & $\begin{array}{l}\text { "....seorang rahib (pendeta) Yahudi dari Bani Qinuqa } \\
\text { bernama Husein bin Sallam, masuk Islam. Secara } \\
\text { diam-diam dia datang menemui Nabi Muhammad }\end{array}$ \\
\hline
\end{tabular}




\begin{tabular}{|c|c|}
\hline b. Toleransi & $\begin{array}{l}\text { saw dan menyatakan ikrarnya untuk masuk Islam. } \\
\text { Karena ia adalah seornag rahib terkemuka dan } \\
\text { berpengaruh di sukunya, maka Nabi } \\
\text { menyembunyikan rahib tersebut di rumahnya. Hal itu } \\
\text { dilakukan untuk melindunginya dari serangan } \\
\text { kaummnya”. (periode Madina) } \\
\text { “....untuk mengatasi terjadinya hal-hal yang tidak } \\
\text { diharapkan, Rasulullah menempuh dua langkah } \\
\text { kebijaksanaan. Pertama: mengadakan perjanjian- } \\
\text { perjanjian dengan kaum yahudi di Madinah-Bani } \\
\text { Nadhir dan Bani Quraidzah untuk menjamin } \\
\text { trwujudnya prinsip hidup berdampingan secara } \\
\text { damai. Kedua: mengirimkan satua-satuan ekspedisi } \\
\text { keberbagai daerah sekitar Madinah yang terdiri dari } \\
\text { kaum Muhajirin dengan dua tugas pokok: mencegah } \\
\text { kemungkinan terjadinya serangan bersenjata yang } \\
\text { hendak dilancarkan oleh kabilah-kabilah yang } \\
\text { bermukim disekitar Madinah, dan mengamati gerak- } \\
\text { gerik kaum musyrikin Quraisy di Makkah sebagai } \\
\text { pusat kekuatan anti Islam dan kaum muslimin. }\end{array}$ \\
\hline & $\begin{array}{l}\text { Nabi Muhammad saw tidak pernah membeda- } \\
\text { bedakan dalam menegakkan keadilan. Dimata Nabi } \\
\text { siapa yang bersalah baik itu keluarga, pejabat } \\
\text { maupun bangsawan semuanya dimata hukum dan } \\
\text { penegakkan hukum semuanya sama. }\end{array}$ \\
\hline $\begin{array}{l}\text { 3. Aspek afektif } \\
\text { a. Empati }\end{array}$ & $\begin{array}{l}\text { “....kemenangan umat Islam dalam perang Khandaq } \\
\text { membuat nama Islam dan kota Madinah semakin } \\
\text { harum dan disegani. Nabi menetapkan ketentuan } \\
\text { yang berlaku bagi seluruh penganut agam kristen. } \\
\text { Mereka tidak diwajibkan membayar pajak yang tidak } \\
\text { berlaku umum. Tidak seorang pun yang dapat } \\
\text { dipaksa keluar dari biaranya. Tidak sebuah gereja } \\
\text { pun boleh dirobohkan untuk dijadikan masjid. } \\
\text { Wanita kristen yang dinikahi oleh laki-laki muslim, } \\
\text { tetap terjamin kebebasan menjalankan agamanya. } \\
\text { “....Nabi Muhammad bekerja bersama-sama pasukan } \\
\text { menggali parit sambil mengatur strategi pertahanan” } \\
\text { “...kemudian Nabi Muhammad saw menyampaikan } \\
\text { beberapa isntruksi kepada pasukannya. Instruksi } \\
\text { tersebut antara lain: jangan sekali-kali beranjak } \\
\text { meninggalkan tempat-tempat pertahanan, melainkan } \\
\text { bersiagalah di tempat masing-masing yang telah }\end{array}$ \\
\hline
\end{tabular}




\begin{tabular}{|l|l|}
\hline & ditentukan. Jangan mulai menyerang, melainkan \\
menunggu perintah. Jangan sekali-kali melancarkan \\
serangan anak panah sementara pihak musuh masih \\
kuat, bidikkan mata anak panah kalian pada sasaran \\
musuh yang jelas. Ketika musuh sudah dekat, \\
lemparkan lembing, tombak kalian. Pedang hanya \\
dipersiapkan sebagai senjata terakhir jika harus \\
bertanding satu lawan satu".
\end{tabular}

Berdasarkan tabel di atas nilai pendidikan perdamaian yang terdapat dalam materi Dakwah Nabi Muhammad saw periode Mekkah dan Madinah tingkat Madrasah Aliyah memiliki aspek-aspek sebagaimana telah di paparkan di atas. Selanjutnya untuk lebih jelasnya penulis gambarkan konsep dari aspek kesesuaian pendidikan perdamaian dalam materi Dakwah Nabi Muhammad Periode Mekkah dan Madinah dan Madinah Tingkat Madrasah Aliyah sebagai berikut:

\begin{tabular}{|l|l|l|l|l|}
\hline \multirow{2}{*}{ No } & \multirow{2}{*}{$\begin{array}{l}\text { Prinsip Nilai Pendidikan } \\
\text { Perdamaian }\end{array}$} & \multicolumn{3}{|c|}{ Hasil Analisis Materi } \\
\cline { 3 - 5 } & Terpenuhi & Cukup & Kurang \\
\hline 1 & Persatuan/Persamaan & $\checkmark$ & & \\
\hline 2 & Kasih Sayang & $\checkmark$ & & \\
\hline 3 & Toleransi & $\checkmark$ & & \\
\hline 4 & Keadilan & $\checkmark$ & & \\
\hline 5 & Komunikasi & $\checkmark$ & & \\
\hline
\end{tabular}

b. Nilai pendidikan perdamaian dalam materi Dakwah Nabi Muhammad saw periode Mekkah dan Madinah tingkat SMA

Materi dakwah Nabi Muhammad saw periode Madinah tingkat SMA berdasarkan hasil analisis menyangkut materi-materi yang memiliki nilai dari pendidikan perdamaian adalah sebagai berikut:

\begin{tabular}{|c|l|}
\hline \multicolumn{2}{|c|}{ Analisis Nilai Pendidikan Perdamaian } \\
\hline $\begin{array}{l}\text { Nilai Pendidikan } \\
\text { Perdamaian }\end{array}$ & \multicolumn{1}{c|}{ Tingkat SMA } \\
\hline 1. Aspek Kognitif & $\begin{array}{l}\text { Nilai pendidikan perdamaian tentang aspek nilai } \\
\text { yang terdapat pada materi keteladanan } \\
\text { Rasulullah saw periode Madinah tingkat SMA } \\
\text { yang berbunyi :“....dalam bidang sosial } \\
\text { kemasyarakatan, Rasulullah SAW telah } \\
\text { melatakkan dasar antara lain adanya persamaan } \\
\text { derajat di antara semua individu, semua } \\
\text { golongan, dan semua bangsa”. }\end{array}$ \\
& $\begin{array}{l}\text { Persatuan dan } \\
\text { “....Rasulullah SAW bermusyawarah dengan } \\
\text { Abu Bakar r.a da Umar bin Khatab tentang }\end{array}$ \\
\hline
\end{tabular}

${ }^{1}$ Lihat, Syamsuri, Pendidikan Agama Islam untuk SMA Kelas X, (Jakarta: Erlangga, 2006), h. 171 


\begin{tabular}{|c|l|}
\hline & $\begin{array}{l}\text { mempersaudarakan antar Muhajirin da Ansar, } \\
\text { sehingga terwujud persatuan yang tagguh" } \\
\text { "...setiap kabilah yang ingin masuk dalam } \\
\text { persekutuan dengan kaum Quraisy atau dengan } \\
\text { kaum Muslimin dibolehkan dan tidak akan } \\
\text { mendapatkan rintangan" }\end{array}$ \\
\hline $\begin{array}{l}\text { 2. Aspek } \\
\text { Psikomotorik }\end{array}$ & \\
a. Kasih Sayang & $\begin{array}{l}\text { "...setiap individu penduduk Madinah mendpat } \\
\text { jaminan kebebasan beragama" (Isi piagam } \\
\text { Madinah) }\end{array}$ \\
b. Toleransi & $\begin{array}{l}\text { "...terjadinya perundingan antara pihak nabi dan } \\
\text { kaum Yahudi perundinagn tersebut melahirkan } \\
\text { a. Empati } \\
\text { b. Komunikasi } \\
\text { sebuah perjanjian, yang dikenal sebagia } \\
\text { perjanjian Hudaibiyah" }\end{array}$ \\
\hline
\end{tabular}

Berdasarkan tabel di atas nilai pendidikan perdamaian yang terdapat dalam materi Dakwah Nabi Muhammad SAW periode Mekkah dan Madinah tingkat Sekolah Menengah Atas memiliki aspek-aspek sebagaimana telah di paparkan di atas. Selanjutnya untuk lebih jelasnya penulis gambarkan konsep penilaian dari aspek kesesuaian pendidikan perdamaian dalam materi Dakwah Nabi Muhammad Periode Mekkah dan Madinah Tingkat Sekolah Menengah Atas sebagai berikut:

\begin{tabular}{|l|l|l|l|l|}
\hline \multirow{2}{*}{ No } & \multirow{2}{*}{ Prinsip Nilai Peace } & \multicolumn{3}{|l|}{ Hasil Analisis Implementasi dalam Materi } \\
\hline & Education & Terpenuhi & Cukup & Kurang \\
\hline 1 & Persatuan & $\checkmark$ & & \\
\hline 2 & Kasih Sayang & & & $\checkmark$ \\
\hline 3 & Toleransi & $\checkmark$ & & \\
\hline 4 & Empati & & & $\checkmark$ \\
\hline 5 & Komunikasi & $\checkmark$ & & \\
\hline
\end{tabular}

Berdasarkan data di atas maka penulis merumuskan tingkat perbandingan materi Dakwah Nabi Muhammad SAW Periode Mekkah Madinah tingkat MA dan SMA sebagai berikut:

Tabel Perbandingan analisis materi MA dan SMA

\begin{tabular}{|l|l|l|l|l|l|l|l|}
\hline \multirow{3}{*}{ No } & \multirow{3}{*}{$\begin{array}{l}\text { Prinsip Nilai Pendidikan } \\
\text { Perdamaian }\end{array}$} & \multicolumn{6}{|c|}{ Hasil Analisis Materi } \\
\cline { 3 - 8 } & & \multicolumn{2}{|c|}{ Tingkat MA } & \multicolumn{3}{|c|}{ Tingkat SMA } \\
\cline { 3 - 8 } & T & C & K & T & C & K \\
\hline 1 & Persatuan & $\checkmark$ & & & & & \\
\hline 2 & Kasih Sayang & $\checkmark$ & & & & & V \\
\hline
\end{tabular}




\begin{tabular}{|l|l|l|l|l|l|l|l|}
\hline 3 & Toleransi & $\checkmark$ & & & & & \\
\hline 4 & Empati & $\checkmark$ & & & & & $\checkmark$ \\
\hline 5 & Komunikasi & $\checkmark$ & & & $\checkmark$ & & \\
\hline
\end{tabular}

Berdasarkan tabel di atas hasil perbandingan yang dilakukan peneliti berdasarkan interpretasi dapat dilihat dan disimpulkan bahwa: dalam nilai pendidikan perdamaian dalam materi Dakwah Nabi Muhammad saw tingkat Madrasah Aliyah memiliki peran yang sangat banyak. Hal ini dapat dibuktikan dalam penyajian materi yang berbentuk deskripsi. Sedangkan untuk tingkat SMA memiliki nilai pendidikan perdamaian yang masih sangat kurang. Hal ini dikarenakan muatan materi yang terdapat dalam materi keteladanan Rasululullah SAW periode Mekkah dan Madinah tingkat SMA masih dikategorikan materi yang kurang lengkap dan jelas. Serta penekanan dari setiap tingkat MA dan SMA dalam materi dakwah Nabi Muhammad SAW periode Mekkah dan Madinah tingkat MA t SMA masih menitik beratkan pada ranah kognitif. Masih sangat sedikit dalam aspek afektif atau nilai.

4. Kritik terhadap materi dakwah Nabi Muhammad saw periode Mekkah dan Madinah tingkat MA dan SMA

Berdasarkan hasil analisis materi yang telah disebutkan sebelumnya. Maka peneliti memberikan kritik terhadap materi Dakwah Nabi Muhammad saw periode Mekkah dan Madinah tingkat MA dan SMA. Materi dakwah Nabi Muhammad saw periode Mekkah dan Madinah tingkat MA dan SMA ini menggunakan kerangka kurikulum yaitu kurikulum tingkat satuan pembelajran (KTSP) sesuai dengan Permenag RI. No. 2 Tahun 2008.

Buku ajar yang memuat tentang Materi Dakwah Nabi Muhammad saw periode Mekkah dan Madinah tingkat MA adalah buku yang dikarang oleh Dr. H. Murodi, MA, alasan peneliti dalam pengambilan buku yang dijadikan sebagai panduan dalam penelitian adalah karena berdasarkan penelusuran buku-buku yang digunakan guru dala mengajar, peneliti menemukan bahwa buku inilah yang dijadikan sebagai buku pegangan siswa dan buku yang banyak beredar dan mudah didapatkan. Selajutnya buku ajar yang memuat tentang materi Dakwah Nabi Muhammad saw periode Mekkah dan Madinah tingkat SMA buku yang peneliti jadikan sebagai buku panduan adalah buku pendidikan agama Islam yang dikarang oleh Syamsuri yang diterbitkan oleh erlangga.

Berdasarkan analisis peneliti, maka peneliti mengungkapkan beberapa kelebihan dan kekurangan yang peneliti dapatkan dalam materi yang tertuang dalam buku pegangangan siswa dan guru kurikulum KTSP sebagai berikut:

1. Materi dakwah Nabi Muhammad saw periode Mekkah dan Madinah di tingkat Madrasah Aliyah tidak hanya berisi kompetensi kognitif semata, tetapi lebih dari itu yang sangat mendasar adalah terletak pada kemampuan menggali nilai, makna, ibrah/hikmah, dalil dan teori dari fakta sejarah yang ada.

2. Materi dakwah Nabi Muhammad saw periode Mekkah dan Madinah di tingkat Sekolah Menengah Atas banyak berisi penekanan kepada kompetensi kognitif saja. Sehingga nilai afeksi sangat kurang, oleh karena itu melalui penelitian ini, masukkan akan perimbangan atas segala kompetensi yang diajarkan melalui materi di tingkat SMA melalui 
kebijakan dari pihak yang berwenang untuk di sejajarkan. Nilai-nilai afeksi yang kurang yang terdapay di tingkat SMA diharapkan melalui hasil penelitian ini menjadi sebuah baha pertimbanagn untuk selalu dimasukkan dala penegmebangan materi ataupun peunyusunan materi. Sehingga citacita dari pendidikan yaitu mencerdaskan bangsa serta memeiliki anak bangsa yang berakhlak dan bermoral dapat dilakukan.

3. Peneliti mendapatkan bahwa alokasi waktu yang diberikan utnuk pembelajaran di tingkat MA dan SMA sangatlah berbeda, sehingganya melalui penelitian ini peneliti ingin menyatakan bahwa dalam pembelajaran sejarah khsusnya dalam pembelajaran Sejara tentang Islam membutuhkan tambahan waktu, sehingga semua materi dapat terselesaikan dengan baik, dan semua materi dapat terangkum dengan baik dalam sebuah buku ajar.

4. Dalam pemilihan kata dalam materi peneliti menyarankan untuk memilih padanan kata yang baik yang dapat mencermikan ke-Islaman. Dalam hal ini peneliti mengngakat kata "perag" yang digunaka dalam salah satu sub pokok bahasan, sebaiknya menggunakan padanan kata lain sehingga tidak menghasilkan interpretasi berbeda. Sehingga kelayakan materi dapat dipertanggungjawabkan.

5. Sangat disadari dalam pelaksanaan Kurikulum Tingkat Satuan pembelajaran (KTSP) yang telah berlangsung sarat akan kekurangan, sehingganya upaya yang sanagt nyata untuk memerbaiki kekurangan yang terdapat dalam kurikulum KTSP adalah dengan merancang kurukulum yang baru yaitu kurikulum K13. Dalam k13 ini lebih banyak menekankan dalam aspek afektif. Dan hal ini sanagat dibutuhkan dalam mengahdapi tantangan zaman saat ini.

Berdasarkan kritik terhadap materi di atas, kedepannya dalam pembelajaran sejarah Islam akan mengalami perbaikan untuk mencapai tujuan pendidikan yang ideal dan lebih baik lagi.

\section{Kesimpulan}

Berdasarkan hasil temuan dan analisis pada Bab-bab sebelumnya dengan mengambil fokus pada materi dakwah Nabi Muhammad saw periode Mekkah dan MAdinah tingkat Madrasah Aliyah dan tingkat Sekolah Menengah Atas mengenai nilai dan aktualisasi peace education dalam materi dakwah Nabi Muhammad saw periode Mekkah dan Madinah, maka dapat ditarik kesimpulan sebagai berikut:

1. Materi Dakwah Nabi Muhammad saw periode Mekkah dan Madinah tingkat Madrasah Aliyah terangkum dalam satu mata pelajaran yaitu mata pelajaran sejarah Kebudayaan Islam. Sedangkat tingkat Sekolah Menengah Atas dakwah Nabi Muhammad saw Periode Mekkah dan Madinah termasuk dalam mata pelajaran Pendidikan Agama Islam aspek tarikh dan kebudayaan. Hal ini mengakibatkan materi-materi yang terdapat dalam penjelasan tingkat SMA cenderung singkat dan tidak mendetail atau dapat dikatakan tidak dijelaskan secara rinci. Dalam materi sirah MA dan SMA ini menitik beratkan pada sejarah dakwah Rasulullah periode Mekkah dan Madinah dengan menekankan aspek mengenai keteladaan akan sikap dan 
perangai dari Nabi Muhammad saw, langkah-langkah yang dilakukan Nabi Muhammad dalam merajut perdamaian serta persatuan dalam perbedaan yang terjadi.

2. Berdasarkan hasil temuan pada rumusan masalah sebelumnya, penulis menemukan adaanya kelebihan pada materi tingkat MA yang memiliki banyak muatan dari nilai dan aktualisasi peace education dibandingkan dengan tingkat SMA. Selain itu pula deskripsi mengenai sejarah yang terdapat dalam materi tingkat MA penjelasannya dilakukan secara detail dan lengkap dibandingkan dengan tingkat SMA yang hanya dideskripsikan secara umum. Penulis mengapresiasi adanya perhatian dari Kementerian Agama dengan telah memasukkan unsur-unsur dari peace eduction dalam muatan-muatan materi. Namun disisi lain, terdapat kesenjangan dalam penyebaran unsur-unsur tersebut dan penyeabarannya masih bersifat umum.

\section{DAFTAR PUSTAKA}

Abdul Karim, Khalil, Hegemoni Quraisy, Yogyakarta: LKiS, 2002.

Ahmad, Munawwar, Ijtihad Politik Gus Dur Analisis Wacana Kritis, Yogyakarta: LkiS, 2010.

Ali Engineer, Ashgar, Asal-Usul Perkembangan Islam, Analisis Pertumbuhan Sosio-Ekonomi, terj. Imam Baehaqy, Yogyakarta: Insistut dan Pustaka Pelajar, 1999.

Ali Salâmah, Awâthif Adîb, Quraisy Qabl al-Islâm Dauruhâ al- Siyâsy wa alIqtishâdy wa al-Dîny, Riyadh: Dâr al-Mirrîkh, 1994.

Armstrong, Karen, Muhammad Sang Nabi Sebuah Biografi Kritis, Surabaya: Risalah Gusti, 2001.

Banna, Hasan "Pendidikan Perdamaian dan Pengentasan Kemiskinan dalam Pemikiran Muhammad Yunus". Skripsi Fakultas Agama Islam Universitas Muhammadiyah Surakarta, 2008.

Buku-standar-isi-sma.pdf- Adobe Reader, h. 52

Bungin, Burhan, Penelitian Kualitatif: Komunikasi, Ekonomi, Kebijakan Publik, dan Ilmu Sosial lainnya, Jakarta: Kencana, 2011

Departemen Agama RI, Al-Quran dan terjemahnya, Bandung:, Jumanatul Ali Art, 2002.

Galtung, Johan, Studi Perdamaian: Perdamaian dan konflik, Pembangunan dan Peradaban, terj. Asnawi \& Safrudin, Surabaya: Pustaka Eureka, 2003. 
Al-Husaini, Al-Hamid, Riwayat Kehidupan Nabi Besar Muhammad saw, Bandung; Pustaka Hidayah, 2011

Haekal, Muhammad Husain, Hayat Muhammad, terj. Ali Audah, Jakarta: Litera Antar Nusa, 2009.

Hisyam, Ibnu Assirotunnabawiyah, Jld. I, Cet II, t.t.p., 1993-1412.

Hitti, Philip K, History of the Arabs, diterjemahkan oleh Cecep Lukman Yasin, Jakarta: PT. Serambi Ilmu Semesta, 2009.

Hornby, A.S, oxford Advanced Learner's Dictionary of Current English, New York: Oxford University Press, 1995.

Ibrahim al-Syarif, Ahmad, Makkah wa al-Madînah al-Munawwarah fì alJâhiliyyah wa Ahd al-Rasûl, Kairo: Daar al-Fikr al-Araby, tt.

J Moleong, Lexy, Metode Penelitian Kualitatif. Bandung: Remaja Rosdakaraa, 2006.

Khisbiyah, Yayah, dkk, "Pendidikan Perdamaian Berbasis Islam (PPBI). Pusat Studi Budaya dan Perubahan Sosial (PSB-PS), 2008.

Lampiran Permenag.pdf-Adobe Reader.

Levy, Reuben Susunan Masyarakat Islam, Jilid II,.

Minan Zuhri, Ahmad, "Pendidikan Damai (Peace Education) dalam Islam". Skripsi, Fakultas

Al-Mubarakfury, Shafiyyurrahman, Shahih Sirah Nabawiyah, Bandung: Darul Aqidah, 2007.

Sirah Nabawiyah Taman Cahaya di atas Cahaya Hidup Rasulullah, Jawa Tengah: Ash-Shaf Media, 2007.

Tarbiyah dan Keguruan UIN Sunan Kalijaga, Yogyakarta, 2010.

Misrawi, Zuhairi, Al-Quran Kitab Toleransi: Inklusifisme, Pluralisme dan Multikulturalisme, Jakarta: Penerbit Fitrah bekerja sama dengan Perhimpunan Pengembangan Pesantren dan Masyarakat (P3M), 2007.

Misrawi, Zuhairi, Madinah Kota Suci, Piagam Madinah, dan Teladan Muhammad SAW. t.t

Muhadjir, Noeng, Metodologi Penelitian Kualitatif, Yogyakarta: Rake Sarasian, 2002.

Musa al-Hariri, Abu, Nabiy al-Rahmah wa Qur"ân al-Muslimîn Bahts fî̀ Mujtma, Makkah. 
Nurcholish, Ahmad, Peacce Education \& Pendidikan Perdamaian Gus Dur, Jakarta: PT Gramedia, 2015.

Nurhakim, Moh,. Sejarah dan Peradaban Islam, Malang: Universitas Muhammadiyah Malang, 2004.

Pulungan, J.Suyuthi, Prinsip-prinsip Pemerintahan dalam Piagam Madinah Ditinjau dari Pandangan Al-Quran, Cetakan ke-II, Jakarta: PT Raja Grafindo Persada, 1996.

Sejarah Hidup Nabi Muhammad saw, bab-8.pdf- Adobe Reader.

Shihab, M. Quraish, Tafsir al-Misbah; Pesan, Kesan, dan Keserasian Al-Quran, Jakarta: Lentera Hati, 2002.

Syalabi, A,. Sejarah Kebudayaan Islam, Jld.I, Jakarta: Pustaka Al-Husna Baru, $1424 \mathrm{H} / 2003$

Syamsuri, Pendidikan Agama Islam untuk SMA kelas X, Jakarta: Erlangga; 2007

Thaha Husein, Fî al-Syi"r al-Jâhily, t.t,.

UNESCO, UNESCO's ASPnet PROJECT \& Interconnections21, International Workshop on Promoting Peace and Conflict Resolution Education in Schools, New York: UNESCO, 2001.

Yatim, Badri, Sejarah Peradaban Islam Dirasah Islamiyah II, Jakarta: PT. Raja Grafindo Persada, 2015

Zaidan, George, Kitâb al-Arab Qabl al- Islâm, Mesir: Mathba"ah Hilâl, 1922, juz 1.

Zamroni, Peace Education, A Reader Volume I, Yogyakarta, Pascasarjana UNY, 2004. 